\title{
Sustentabilidade de empreendimentos econômicos solidários: análise da Cooperativa dos Fruticultores de Abaetetuba
}

\author{
Anderson Roberto Pires e Silva \\ Universidade Federal do Pará (UFPA) \\ Maria José de Souza Barbosa \\ Universidade Federal do Pará (UFPA) \\ Francivaldo dos Santos Albuquerque \\ Universidade Federal do Pará (UFPA)
}

O estudo tem por objetivo realizar uma análise do processo de incubação, uma tecnologia social voltada à sustentabilidade de empreendimentos econômicos solidários. Trata-se de mostrar a ação da Incubadora Tecnológica de Cooperativas Populares e Empreendimentos Solidários (ITCPES), um programa de ensino, pesquisa e extensão junto à Cooperativa dos Fruticultores de Abaetetuba (Cofruta). Partiu-se da pesquisa exploratória-descritiva sob uma abordagem qualitativa-quantitativa para demonstrar a sustentabilidade a partir das dimensões: econômica, social, política, gestão e formação. Com base nesses indicadores chegou-se ao resultado de que a Incubadora contribui para a sustentabilidade da Cofruta, principalmente, no que diz respeito ao planejamento, ao controle e à necessidade de diversificação da produção.

Palavras-chave: incubação; empreendimentos econômicos solidários; sustentabilidade.

Sustentabilidad de los emprendimientos económicos solidarios: análisis de la Cooperativa de Fruticultores de Abaetetuba

El estudio tiene como objetivo analizar el proceso de incubación, una tecnología social orientada a la sustentabilidad de los emprendimientos económicos solidarios. Este es el análisis de la Incubadora Tecnológica de Cooperativas Populares y Emprendimientos Solidarios (ITCPES), un programa de enseñanza, investigación y extensión desarrollado junto con la Cooperativa de Fruticultores de Abaetetuba (COFRUTA). Se trata de una investigación de carácter exploratorio-descriptivo basada en un enfoque cualitativo y cuantitativo, que busca abordar la sustentabilidad a partir de las siguientes dimensiones: económica, social, política, gestión y formación. Con base en esos indicadores se llegó a la conclusión de que la Incubadora contribuye a la sustentabilidad de COFRUTA, especialmente con respecto a la planificación, el control y la necesidad de diversificar la producción.

Palabras clave: incubación; emprendimientos económicos solidarios; sustentabilidad.

Artigo recebido em 21 jun. 2012 e aceito em 15 maio 2013. 


\begin{abstract}
Sustainability of solidarity economic enterprises: analyses of the Fruit Growers Cooperative from Abaetetuba

The study aims to analysis the incubation processes, a social technology to the sustainability of solidarity economic enterprises. This work shows the Technological Incubator of Popular Cooperatives and Enterprises Solidarity (ITCPES), a program of teaching, research and extension to the "Cooperativa de Fruticultores de Abaetetuba (COFRUTA)". We started from the exploratory-descriptive in a qualitative and quantitative approach to demonstrate the process on dimensions of sustainability as: economic, social, political, management and training. Came to the result that the Incubator contributes to the sustainability of COFRUTA, especially with regard to planning, control and the need to diversify production.
\end{abstract}

KEYWORDs: incubation; solidarity economic enterprises; sustainability.

\title{
1. Introdução
}

Para se entender as contribuições e desafios da Incubadora Tecnológica de Cooperativas Populares e Empreendimentos Solidários (ITCPES) em relação ao processo de incubação de empreendimentos econômicos solidários (EES) é preciso se deter inicialmente na economia solidária (ES), seus conceitos e interpretações da perspectiva brasileira e internacional para, em seguida, destacar o papel da incubação dos empreendimentos econômicos solidários (EES), enquanto tecnologia social voltada à sustentabilidade desses empreendimentos e, em consequência, da economia solidária.

Considerando as experiências no final do século XX, quando a globalização acelerada do capital levou à redução dos postos de empregos, quando parecia inexorável o desemprego crescente e, ainda, com a desilusão em relação à experiência socialista, uma nova proposta se lançou a resgatar a dignidade das pessoas em situação de exclusão - a economia solidária. A principal força dessa proposta talvez seja a forma "subversiva" de atuar na economia sem se submeter aos princípios capitalistas de competitividade e de lucro privado, dentro de uma lógica de cooperação, de igualdade, de liberdade, autonomia e de respeito ao meio ambiente (Nunes, 2009).

No Brasil, a busca de alternativas à crise do emprego vem transformando a economia solidária em uma das principais formas de (re)organização da sociedade, para a obtenção de trabalho e renda, por meio de um modo diferenciado de produção e distribuição. Na economia solidária pode-se cuidar do futuro na prática de hoje, priorizando-se o homem, percebendo-se que a estrutura social pode favorecer as pessoas, para que possam ser respeitadas e encontrem seu lugar no processo coletivo, para além da luta pelo poder como um fim em si mesmo.

Nesta perspectiva, a economia solidária procura desenvolver suas atividades sob oito princípios básicos: autogestão, democracia, participação, igualitarismo, cooperação, autossustentabilidade, desenvolvimento humano e responsabilidade social (Gaiger, 2003). 
Das diversas formas de organização dos trabalhadores em EES destacam-se para esse estudo as cooperativas, reconhecidas como associações autônomas de pessoas que se unem voluntariamente e constituem uma entidade de propriedade comum, a fim de satisfazer as aspirações econômicas, sociais e culturais. Para que tais EES atinjam seus objetivos de geração de trabalho e renda, assim como de proporcionar o bem-estar da coletividade, precisam alcançar sua sustentabilidade (Reis, 2005).

Os elementos que influenciam na sustentabilidade podem variar em função das características específicas de cada empreendimento. No caso específico deste estudo, as características que regem uma cooperativa são o tratamento para o ato cooperativo e não cooperativo, seus processos produtivo e comercial, o capital de giro, a articulação em redes de relacionamentos, a coesão social, a ação pública, os parceiros governamentais e não governamentais, seu processo de gestão, formação, dentre outros.

A sustentabilidade, neste artigo, é analisada de modo multidimensional, agrupada sob as dimensões econômicas, sociais, políticas, gestão e formação, a fim de compreender como os EES são capazes de se manter no mercado, atendendo aos princípios da solidariedade. Portanto, a análise não se dá apenas pela esfera econômica ou social e sim pela inter-relação entre as diversas dimensões (França Filho e Laville, 2004; Reis, 2005).

A sustentabilidade dos EES é resultante, na maioria das vezes, do processo de incubação desenvolvido pelo apoio das universidades federais na forma de projeto ou programa de pesquisa, ensino e extensão. Os programas denominados Incubadoras Tecnológicas de Cooperativas Populares e Empreendimentos Solidários (ITCPES), por meio de metodologia específica, desenvolvem cursos, oficinas, seminários e acompanhamentos técnicos, a fim de preparar os EES para que desenvolvam a autogestão e consigam caminhar "sozinhos" (ITCPES, 2008; Eid, 2004; Nunes, 2009).

O processo de incubação da Cooperativa dos Fruticultores de Abaetetuba (Cofruta) foi desenvolvido pela ITCPES/UFPA e teve uma duração de aproximadamente cinco anos. Atualmente, a Cooperativa passa pela fase de desincubação. Nesse sentido, questiona-se: de que modo a incubação contribui para a sustentabilidade dos empreendimentos econômicos solidários, a partir da análise da Cofruta?

A pesquisa mostra, a partir da realidade da Cofruta, o processo de incubação sob a ótica da sustentabilidade. Portanto, trata-se de uma avaliação, com dois eixos de análise: por um lado, os cooperados da Cofruta passaram a identificar as contribuições do processo de incubação desenvolvido pela ITCPES/UFPA e, por outro, os técnicos, professores e bolsistas da incubadora refletiram sobre suas ações de incubação, um constante processo de construção.

\section{Debate sobre a economia solidária na perspectiva da sustentabilidade}

Laville e Gaiger (2009) ressaltam que a economia solidária é um conceito amplamente utilizado em vários continentes, com acepções variadas de solidariedade, em contraste com o 
individualismo utilitarista que caracteriza o comportamento econômico predominante nas sociedades de mercado.

Assim como o significado, a origem ou o desenvolvimento do termo economia solidária é discutido por estudiosos como Gaiger (2009), Coraggio (2003), França Filho e Laville (2004), Laville e Gaiger (2009), Singer (2000, 2002), Eid (2004) e Wellen (2012). No entanto, esses autores convergem na ideia de que o termo foi cunhado na América Latina, na década de 1990, quando, por iniciativa de cidadãos, produtores e consumidores, despontaram inúmeras atividades econômicas, organizadas segundo princípios de cooperação, autonomia e autogestão democrática.

A expressão economia solidária multiplicou-se em diversas formas: coletivos de geração de renda, cantinas populares, cooperativas de produção e comercialização, empresas recuperadas (autogestionárias), redes e clubes de troca, sistemas de comércio justo e de finanças, grupos de produção ecológica, comunidades produtivas autóctones, associações de mulheres, serviços de proximidade etc., por apresentar a solidariedade como primazia ao interesse individual e o ganho material, manifestada pela socialização dos recursos produtivos e a adoção de critérios igualitários (Gaiger, 2009; Coraggio, 2003; Singer, 2002).

O Fórum Brasileiro de Economia Solidária (FBES) e a Secretaria Nacional de Economia Solidária (Senaes) entendem a economia solidária como um jeito diferente de produzir, vender, comprar e trocar o que é preciso para viver, sem explorar ninguém, sem querer levar vantagem, sem destruir o ambiente; ou seja, no lugar da devastação do meio ambiente, a economia solidária se propõe a cuidar da natureza, e, no lugar do autoritarismo de chefes ou patrões, a democracia entre todos decidindo juntos e compartilhando igualmente o que se ganha e o que se perde.

A economia solidária é entendida como uma estratégia de enfrentamento da exclusão social e da precarização do trabalho, sustentada em formas coletivas, justas e solidárias de geração de trabalho e renda, com objetivos comuns e sociais, a fim de transformá-los em ação, com processos administrativos consistentes e adaptados às suas características, condição sine qua non para a sustentabilidade (Gaiger, 2009).

Para Barbosa (2012a), a sustentabilidade está ancorada na formação de competência técnica e habilidades para gerenciar os processos socioprodutivos, afirmando o protagonismo do trabalho associado e suas experiências concretas, que passam a ser redimensionados com base na tecnologia social, cujo "objetivo é alcançar a sustentabilidade social, econômica e ambiental" (Eid, 2012).

Assim, a sustentabilidade dos empreendimentos econômicos solidários, com base "em tecnologias sociais aplicadas ao desenvolvimento da Amazônia, no lugar da universidade, torna-se uma tarefa importante (...) no capitalismo de redes, na sociedade do conhecimento e no capitalismo cognitivo" (Barbosa, 2012b).

Problematizar a questão da sustentabilidade dos empreendimentos econômicos solidários na perspectiva das tecnologias sociais e do desenvolvimento na Amazônia é um desafio que precisa ser enfrentado, tanto na Amazônia da globalização, quanto na Amazônia local, 
posto que ela não está isolada (Barbosa, 2012b). Neste sentido é que se busca discutir a sustentabilidade da Cofruta com base no desenvolvimento sustentável desta região continental.

\section{A Incubadora Tecnológica de Cooperativas Populares e Empreendimentos Solidários (ITCPES/UFPA)}

A Incubadora Tecnológica de Cooperativas Populares e Empreendimentos Solidários da UFPA surge em 2001 com recursos da Pró-reitoria de Extensão (Proex/UFPA). No início, tratava-se apenas de um projeto de extensão com atuação restrita na Região Metropolitana de Belém; no entanto, com o aumento das demandas sociais, seu campo de atuação se estendeu para a zona rural, na medida em que vai ao encontro tanto das iniciativas espontâneas de trabalhadores historicamente excluídos do mercado formal, quanto do suporte técnico e teórico à formação do trabalho coletivo.

Em outras palavras, a ITCPES/UFPA é um ambiente propício para estimular o desenvolvimento de pequenos empreendimentos populares, mediante suporte gerencial, formação cooperativa e associativa, científica, tecnológica, estudo de mercado e comercialização, apoio de infraestrutura e identificação de linhas de financiamento e fomento, proporcionando aos empreendimentos assistidos, inseridos no processo de incubação, condições favoráveis à sustentabilidade de suas atividades econômicas, sociais, culturais e ambientais (ITCPES, 2008).

A captação de recursos ${ }^{1}$ é realizada por diversos projetos, gerando o fortalecimento do intercâmbio com instituições de ensino superior nacional, regional, local e internacional. Isto contribui efetivamente para a articulação do tripé pesquisa/ensino/extensão, criando condições para transformar o projeto ITCPES/UFPA em um Programa, atualmente um dos maiores laboratórios de experimentação de processos de ensino-aprendizagem sobre metodologias participativas e trocas de saberes, de modo interdisciplinar.

Assim, a articulação com as agências de fomento tem permitido a inserção de profissionais de nível superior, especialistas e/ou mestrandos/mestres, das áreas de economia, contabilidade, serviço social, sociologia, nutrição, engenharia de alimentos, administração, agronomia, engenharia ambiental, engenharia de produção, design, dentre outros; possibilitando a oferta de bolsas de iniciação científica e de extensão para os discentes das áreas de conhecimentos afins ao programa.

Na região Norte, a ITCPES/UFPA tornou-se referência na metodologia de incubação de empreendimentos solidários, contribuindo para a criação de incubadoras nas universidades federais do Acre (Ufac), Amapá (Unifap), Roraima (UFRR), Rondônia (Unir), Universidade

\footnotetext{
${ }^{1}$ A Incubadora tem obtido êxito na realização de convênios com diversos órgãos de âmbito nacional e internacional, como Fundação Banco do Brasil (FBB), Financiadora de Estudos e Projetos (Finep), Agencia Española de Cooperación Internacional para el Desarrollo (Aeci), Organização Intereclesiástica para a Cooperação ao Desenvolvimento (Icco), Ministério do Desenvolvimento Social (MDS), Ministério do Trabalho e Emprego (MTE), Ministério do Desenvolvimento Agrário (MDA), Ministério do Turismo (MTur), governo estadual, prefeituras municipais e CNPq.
} 
Federal Rural da Amazônia (Ufra), ITCPES do Campus de Marabá (UFPA), no Instituto Federal de Educação, Ciência e Tecnologia (IFPA/Campus Castanhal), Incubadora do Campus de Breves e o fortalecimento da Incubadora da Universidade Estadual do Tocantins (Unitins).

Segundo Barbosa (2006:64), “o trabalho em equipe gera uma ação unificada, pois é parte de um todo, não podendo ser visto sob uma lógica de segmentação nem isolamento de cada ação ou área de conhecimento". É aí que a interdisciplinaridade ganha sentido e encontra seu ponto de apoio, para reconectar as teias da vida social, ou seja, economia, política e sociedade, sob o ponto de vista do trabalho coletivo que se quer criativo, o qual potencializa as atividades humanas concretas.

Nesse sentido, a crítica e a autocrítica de suas atividades tornam-se o eixo central da ação-intervenção-reflexão. Nesse âmbito ocorre o debate e a troca de experiências entre professores, pesquisadores, técnicos, estudantes universitários e os diversos interlocutores, na perspectiva de superação da atividade individual, em campos de conhecimentos fragmentados, visando entender a complexidade colocada pela totalidade social. Além do espaço importante de produção teórica materializada em artigos, monografias, dissertações de mestrado e teses de doutorado.

A metodologia desenvolvida pela ITCPES é baseada na pesquisa-ação teorizada por Thiollent (2005), na educação popular difundida por Freire (1989), como também na pesquisa participante de Brandão (1981), além da metodologia de incubação de Eid (2001), sob um intenso movimento de adequação a cada projeto. Portanto, é ampliada pelos próprios conhecimentos decorrentes das experiências e reflexões da equipe, haja vista que se trata de uma forma dinâmica de interpretar a realidade dos sujeitos envolvidos nos empreendimentos, tendo em conta que é na dinâmica do próprio trabalho que se constroem os passos seguintes.

Dessa maneira, a metodologia desenvolvida pela ITCPES/UFPA leva em consideração, sobretudo, a realidade dos grupos acompanhados e o contexto amazônico, pois se trata de uma realidade extremamente complexa, o que tem exigido da equipe um esforço suplementar para a compreensão das dinâmicas concretas dos empreendimentos econômicos solidários (EES).

Um traço marcante no processo de incubação é o mapeamento da trajetória de vida dos cooperados, o qual é feito pela técnica da linha do tempo, buscando-se, com isso, contribuir para o desenvolvimento da coesão social, através da responsabilização de cada indivíduo para o sucesso do projeto coletivo (Eid, 2004; Nunes, 2009).

As atividades de campo, realizadas nas etapas iniciais, visam à construção do diagnóstico dos empreendimentos, fase que o programa convenciona denominar de pré-incubação, enquanto as atividades relacionadas a cursos, oficinas e visitas técnicas são a incubação propriamente dita, quando os trabalhadores dos empreendimentos solidários estão preparados para operar, de maneira autônoma, de acordo com o plano de negócio, dando continuidade à organização, gestão, produção e comercialização, sem a supervisão diária dos técnicos, isto é, vivendo cotidianamente o processo de autogestão e caminhando para a sustentabilidade econômica e social de longo prazo; nesse momento, pode-se dizer que o mesmo passa pelo processo de desincubação (Nunes, 2009; ITCPES, 2008). 


\section{Sustentabilidade de empreendimentos econômicos solidários à luz das dimensões econômica, política, social, gestão e formação}

\subsection{Um debate sobre a sustentabilidade dos EES}

Para se discutir a sustentabilidade dos EES, faz-se necessário entender que a economia solidária não se limita à existência da dimensão econômica e social, na medida em que busca a inter-relação com outras dimensões, como a política, a gestão e a formação, pois os grupos organizados desenvolvem uma dinâmica coletiva na elaboração das atividades de produção e comercialização, com vistas ao enfrentamento de problemas gerais, que podem estar situados no âmbito da educação, cultura, saúde, alimentação, moradia, meio ambiente, transporte, armazenamento etc. (França Filho e Laville, 2004).

A sustentabilidade é entendida como a capacidade que as organizações têm de se manter em funcionamento, cumprindo os objetivos a que se propõem, em consonância com a filosofia da economia solidária; portanto, não se restringindo ao resultado financeiro, ou à capacidade de gerar receita com superavit em relação aos custos operacionais e obter sobra, seja através da venda de produtos ou pela prestação de serviços, há a exigência de resultado político e social (Reis, 2005).

As dificuldades dos EES em manter a sustentabilidade devem-se, em princípio, ao fato de ter seu foco apenas no econômico ou apenas no social. Quando o foco é apenas no econômico, corre-se o risco de não atender aos princípios que lhe deram origem, ou seja, a solidariedade, a reciprocidade e a cooperação democrática. Quando o foco é apenas no social, o empreendimento fica na dependência de apoio de parceiros (doações) ou aprovação de projetos via órgãos financiadores para poder se operacionalizar, o que de fato tem emperrado o processo de autogestão, caracterizando-se uma política assistencialista.

A sustentabilidade é aqui compreendida a partir da articulação entre as diferentes dimensões, sem a primazia de uma sobre a outra. Aspectos econômicos, sobretudo quando se pensa em iniciativas empreendidas em busca de geração de trabalho e renda, são fundamentais à consolidação dos empreendimentos; todavia, o social e o político também terão influências significativas na gestão e na sustentabilidade (França Filho e Laville, 2004; Reis, 2005).

Os empreendimentos de economia solidária têm como princípio a organização sob as dimensões econômica, social, política e, segundo se compreende, acrescenta-se nesse estudo a gestão e a formação como elementos essenciais à sustentabilidade dos EES.

Para a análise da Cofruta partiu-se dos estudos de Reis (2005), acrescentando-se mais duas dimensões, ou seja, a formação e a gestão, com base nos estudos realizados e na experiência concreta de incubação na ITCPES.

Isto porque, de acordo com Eid (2012:31), a racionalidade técnica precisa estar subordinada à racionalidade social, a fim de dar sustentação à cooperação, tendo em vista que "a manutenção de cada posto de trabalho tem prioridade maior do que a expansão do empreendimento". Ainda alinhando-se ao pensamento deste autor, a formação dá sustentação efetiva aos trabalhadores associados para a conquista da sustentabilidade. Assim, a incubação é 
tecnologia social adequada na medida em que possibilita formação e assessoria técnica como condição de se trabalhar as duas dimensões acrescidas às descobertas de Reis (2005) sobre a sustentabilidade dos empreendimentos econômicos solidários. Neste sentido, as dimensões precisam estar interligadas, como se busca demonstrar com os indicadores relacionados no quadro analítico abaixo.

\section{Quadro 1 \\ Quadro analítico para entender a sustentabilidade de empreendimentos econômicos solidários}

\begin{tabular}{|c|c|c|}
\hline Dimensão & Componentes & Indicadores \\
\hline \multirow{7}{*}{ Econômica } & \multirow{2}{*}{ Mercantil } & Venda produtos/serviços \\
\hline & & Subsídios governamentais (nível institucional) \\
\hline & \multirow{3}{*}{ Não mercantil } & Subsídios não governamentais (nível institucional) \\
\hline & & Doaç̃̃es monetárias (nível individual) \\
\hline & & Trabalho voluntário \\
\hline & \multirow[b]{2}{*}{ Não monetário } & Doações não monetárias \\
\hline & & $\begin{array}{l}\text { Práticas reciprocitárias (ações comunitárias, mutirões, formas } \\
\text { de troca/dádiva) }\end{array}$ \\
\hline \multirow{2}{*}{ Sociocultural } & \multirow{2}{*}{ Construção do vínculo associativo } & Padrão de sociabilidade \\
\hline & & Grau de coesão social \\
\hline \multirow{4}{*}{ Política } & \multirow{2}{*}{ Nível interno } & Grau de democracia interna \\
\hline & & Grau de comprometimento \\
\hline & \multirow{2}{*}{ Nível institucional } & Existência de ação pública \\
\hline & & Nível de articulação em redes \\
\hline \multirow{5}{*}{ Gestão } & \multirow{4}{*}{ Processo administrativo } & Nível de planejamento \\
\hline & & Nível de organização \\
\hline & & Nível de direção \\
\hline & & Nível de controle \\
\hline & Autogestão & Nível de autonomia \\
\hline \multirow{2}{*}{ Formação } & Cooperativismo/Associativismo & Nível de cooperação \\
\hline & Conhecimentos técnicos & Cursos e oficinas \\
\hline
\end{tabular}

Fonte: Elaborado pelos autores a partir de Reis (2005), com acréscimo das dimensões gestão e formação.

\section{Procedimentos metodológicos adotados}

A análise dos resultados alcançados pela Cofruta, no que se refere à sustentabilidade, assumiu caráter exploratório-descritivo devido à preocupação com a ação prática (Gil, 2010), fundamentando-se nos indicadores relacionados e variáveis em acordo com o quadro analítico do item 
anterior. Para isto, buscou-se centrar a análise em dois eixos principais: a Cofruta e a ITCPES/ UFPA, e adotou-se o método quali-quanti para a coleta de dados, a fim de se obter o máximo de informações e eventos (Creswell, 2007) para o alcance dos objetivos da pesquisa.

Ressalta-se que a análise de um único ou de poucos empreendimentos fornece uma base frágil para a generalização; no entanto, o propósito do estudo foi de proporcionar uma visão global do problema a fim de identificar possíveis fatores que influenciam ou são por eles influenciados. Nesse sentido, deu-se a escolha da Cofruta, um empreendimento econômico solidário, composto por 137 cooperados, dividido em seis setores de produção, ${ }^{2}$ e que atualmente passa pelo processo de desincubação. ${ }^{3}$

A amostra relativa à Cofruta realizou-se em caráter misto, envolvendo 51 cooperados, mediante uma escolha aleatória para responder ao questionário ${ }^{4}$ e uma escolha selecionada para os coordenadores dos setores e da diretoria da Cooperativa. A distribuição da amostra por setores ficou de acordo com a tabela abaixo.

Tabela 1

Setores de produção da Cofruta

\begin{tabular}{|lcc|}
\hline Setores & Frequência & Percentual \\
\hline Campompema & 10 & $20 \%$ \\
Maracapucu & 11 & $22 \%$ \\
Urubuéua & 6 & $12 \%$ \\
Furo Gentil & 7 & $14 \%$ \\
Cataiandeua & 11 & $22 \%$ \\
Maúba & 6 & $12 \%$ \\
Total & 51 & $100 \%$ \\
\hline
\end{tabular}

Fonte: Elaborado pelos autores.

Em relação à equipe da Incubadora, a amostra envolveu 30 pessoas entre professores, técnicos e bolsistas. Também se deu em caráter misto e sob o mesmo critério de seleção dos membros da Cofruta, de forma que pelo menos fosse entrevistado um participante de cada núcleo ${ }^{5}$ da Incubadora, dando preferência para os integrantes mais antigos, que pudessem

\footnotetext{
${ }^{2}$ São eles: Campompema, Maracapucu, Furo Gentil, Urubuéua, Maúba e Cataiandeua, sendo quatro na região de ilhas (alagados) e dois na região de estradas (terra firme), localizados na Região do Baixo Tocantins (PA), no município de Abaetetuba.

${ }^{3}$ Desincubação é o processo de autonomização dos empreendimentos em relação à formação e ao acompanhamento técnico da incubadora, o que significa que os empreendimentos já têm condições de se autogerirem.

${ }^{4}$ Foram elaborados, na realidade, dois questionários: um aos cooperados, composto por 60 questões, abordando as dimensões econômicas, social, política, gestão e formação, e outro para a equipe técnica da Incubadora, com 20 questões, abordando o conhecimento sobre o processo de incubação da Cofruta.

${ }^{5}$ Núcleo de gestão, núcleo econômico, núcleo social e de tecnologia de alimentos.
} 
contribuir de maneira mais efetiva à pesquisa, uma vez que os novos ainda possuíam pouca informação em relação à incubação e à sustentabilidade da Cofruta.

No que se refere à coleta e ao controle de dados foram utilizados dois procedimentos: o primeiro relativo à pesquisa bibliográfica e documental, visando estabelecer as categorias teórico-analíticas e a interpretação dos dados secundários em documentos como estatuto, relatórios, atas de assembleias e reuniões (Gil, 2010).

O segundo se refere ao levantamento dos dados primários que se desenvolveu na Cofruta, assim como na ITCPES/UFPA, levando em consideração o processo de incubação daquela por esta. Buscou-se apreender os fenômenos que poderiam caracterizar a sustentabilidade ou não da Cofruta, com base na incubação.

Isso significa que os próprios cooperados identificaram os resultados (conquistas e desafios) alcançados no processo de incubação. Esta etapa visou conhecer a aplicação da metodologia de incubação, baseada na pesquisa-ação, tentando mensurar o nível de eficiência e eficácia da equipe técnica da Incubadora em relação à sustentabilidade da Cofruta, sob o ponto de vista dos cooperados.

Num segundo momento, ocorreu a aplicação dos questionários à equipe técnica da ITCPES/UFPA, a fim de coletar dados que possibilitassem a análise de sua atuação sob sua própria ótica de incubação de EES, em especial, da Cofruta, identificando pontos fortes e fracos, na construção da sustentabilidade da Cooperativa.

Por se tratar de uma pesquisa de caráter científico, os textos oriundos das entrevistas e dos questionários foram estudados mediante a análise de conteúdo, o que permitiu classificar palavras, frases, ou mesmo parágrafos em categorias de conteúdo, a fim de dar significado às respostas obtidas, evidenciando as interfaces no nível da análise categorial das temáticas, em acordo com as proposições dos sujeitos que constituíram a base do estudo (Bardin, 1977). Posteriormente, a análise foi confrontada com as diferentes dimensões e correlacionada a categorias e variáveis, para, desta forma, estabelecer os nexos entre o processo de incubação e a sustentabilidade da Cofruta.

\section{A Cooperativa dos Fruticultores de Abaetetuba (Cofruta): a luz da sustentabilidade}

A Cofruta está localizada no Território da Cidadania Baixo Tocantins (PA), mais especificamente na cidade de Abaetetuba. Foi criada em 2 de março de 2002, com o apoio da Associação de Desenvolvimento dos Mini e Pequenos Agricultores de Abaetetuba (Adempa) e do Sindicato dos Trabalhadores Rurais de Abaetetuba (STR), com o objetivo de elevar o potencial produtivo, organizacional e comercial dos produtos oriundos da agricultura familiar e da economia solidária. Atualmente, possui um quadro social com 137 sócios, sendo 109 homens e 28 mulheres, tendo como objetivo principal o desenvolvimento da comercialização da produção de frutos e derivados, bens e serviços, a partir das seguintes atividades: 
a. Incentivar e coordenar a produção familiar rural, nas áreas pertencentes aos associados;

b. Viabilizar o acesso e comercializar os bens de consumo de frutos e derivados necessários às famílias dos associados como, no limite dos interesses da Cooperativa e da lei, os não sócios;

c. Viabilizar a comercialização dos frutos e derivados por ela incentivada dos associados e, no limite do interesse da Cooperativa e da lei, os não sócios;

d. Implantar sistema de agroindústria em produtos de interesses dos seus associados;

e. Realizar operações de compra e venda de frutos e derivados que possam atender as necessidades dos seus associados, sem comprometer o equilíbrio financeiro da Cooperativa (Estatuto, capítulo II; dos objetivos art. 5o, § 1o).

O desenvolvimento sustentável da região faz parte da agenda da Cofruta, uma vez que busca alcançar o sucesso do empreendimento sem devastar o ambiente, preservando-o para que "os filhos dos seus filhos possam usufruir e desfrutar da natureza, ou mesmo colher os frutos que foram plantados hoje e que só amadurecem em longo prazo". ${ }^{6}$

A Cofruta desenvolve seus produtos a partir de frutos tropicais típicos da região, beneficiando-os sem o uso de aditivos químicos, nem mesmo corantes ou conservantes, a fim de garantir todas as propriedades naturais dos frutos, com exceção dos xaropes frios, que necessitam de alguns elementos para manter suas substâncias alimentícias.

Por adotar práticas voltadas ao trabalho coletivo, a Cofruta desenvolve uma gestão democrática, sendo o órgão máximo de deliberação a assembleia geral realizada anualmente, na qual são decididas todas as questões relativas ao planejamento e às estratégias de gestão, tais como: prestação de contas dos órgãos de administração; distribuição dos fundos e rateios das sobras, perdas e prejuízos; eleição dos componentes dos órgãos de administração e conselho fiscal; avaliação ou controle das atividades em geral; planejamento de atividades para o ano; fixação de honorários "pró-labore" da diretoria, entre outros assuntos de interesse da cooperativa.

Com a finalidade de facilitar a organização do quadro social da cooperativa, esta dividiu seu território em seis setores: Campompema, Maracapucu, Urubuéua, Furo Gentil, Cataiandeua e Maúba, e juntamente com os sócios de cada setor elege um representante que funciona como elo entre o(a) agricultor(a) sócio(a) e a cooperativa, cuja função é convocar os demais cooperados para as reuniões, repassar informações aos cooperados, organizar os produtores para trazerem os frutos, providenciar o transporte dos mesmos para a fábrica e influenciar a entrada de novos cooperados.

Quando há a necessidade de entrada de matéria-prima na unidade fabril, o gerente da fábrica entra em contato com o coordenador de produção e faz a solicitação; este, por sua

${ }^{6}$ Depoimento de um dirigente da Cofruta. 
vez, faz contato com os representantes de setores para averiguar qual setor tem a produção disponível.

Este ciclo operacional (cooperado, cooperativa e mercado) é caracterizado como o ato cooperativo. Segundo a Lei no 5.764/1971 em seu art. 79, atos cooperativos são aqueles "praticados entre as cooperativas e seus associados, entre estes e aquelas e pelas cooperativas entre si quando associados, para a consecução dos objetivos sociais".

No entanto, se por acaso os cooperados mostrarem incapacidade produtiva ou não possuírem produtos demandados pelo mercado, nada impede que a Cofruta busque esse produto entre outros agricultores, mesmo não sendo estes membros da cooperativa, o que caracteriza o Ato Não Cooperado (Santos, Gouveia e Vieira, 2008).

Inseridos na lógica competitiva de mercado, os agricultores familiares não restringem a produção à subsistência. Ao contrário, além de produzir, passaram a beneficiar, processar e comercializar seus produtos; no entanto, este tipo de agricultura encontra dificuldades em virtude de suas limitações relacionadas a informações ágeis nos aspectos da produção, armazenamento, embalagem e, principalmente, comercialização.

\section{A Cofruta sob as dimensões da sustentabilidade}

\subsection{A dimensão econômica}

Para a compreensão da dimensão econômica analisam-se os componentes mercantil, não mercantil e o não econômico (ou não monetário). Segundo relatos dos cooperados, a Cofruta surgiu para desenvolver o beneficiamento (industrialização) e a comercialização da produção dos fruticultores associados à Adempa, uma vez que a associação não possui (legalmente) finalidade de comercialização. No início, a produção era praticamente monocultura, sendo o açaí ${ }^{7}$ o produto de destaque. No entanto, o fato de a produção não se dar durante todo o ano fez com que os agricultores passassem à policultura e a pensar em outros produtos, como sementes oleaginosas ${ }^{8}$ e o próprio beneficiamento das frutas, mediante a produção de polpas, geleias, sucos, xaropes e doces.

Atualmente, com um mix de aproximadamente 40 produtos diferentes, divididos em sete segmentos — produtos in natura, polpa, geleia, suco, xarope, doce e semente —, o açaí ainda é destaque, tanto no segmento in natura, quanto no de polpa e geleia, correspondendo a praticamente $20 \%$ da comercialização da cooperativa. Seguindo o açaí, tem-se o cupuaçu com uma produção relevante nos segmentos de polpa, geleia, suco e xarope. Outros produtos, como abacaxi, acerola, maracujá e taperebá (polpa, suco e xarope), merecem destaque. Atu-

\footnotetext{
${ }^{7}$ Conhecido cientificamente por Euterpe oleracea.

${ }^{8}$ Andiroba, muru-muru, patauá.
} 
almente, a produção de sementes oleaginosas como muru-muru, andiroba e patauá também tem se destacado, correspondendo a 7\% da comercialização da Cooperativa.

Os produtos que apresentam maior rentabilidade são o açaí in natura (36\%), seguido da polpa de cupuaçu (31\%) e da polpa de açaí (16\%). Porém, quando analisados os segmentos, observa-se que as polpas possuem maior rentabilidade (58\%), seguidas dos produtos in natura (37\%), confirmando, assim, a importância da agroindústria no processo de agregação de valor à produção.

No período de entressafra do açaí, o interesse e a dedicação dos cooperados em relação à Cooperativa diminuem consideravelmente, pois, sem produto, os mesmos procuram outras atividades a fim de obter renda para manter suas famílias. Isto demonstra a importância da diversificação da produção da Cofruta para sua sustentabilidade.

A maioria (88\%) dos cooperados pesquisados demonstrou não ter conhecimento da arrecadação (receita), nem da despesa média mensal da Cofruta. No entanto, comungam do posicionamento de que a receita obtida pela Cooperativa é suficiente para pagar as despesas e ainda obter sobra, fato que explica a permanência deles como cooperados e a confiança em relação à Cofruta, componentes indicativos de sustentabilidade.

Os cooperados comentaram que, antes da criação da Cofruta, não possuíam renda fixa, com a qual pudessem contar todo mês. Com a Cooperativa, eles continuam sem uma renda fixa, porém possuem a expectativa de uma renda média mensal entre um e dois salários mínimos, nos períodos de entressafra, e três a quatro salários mínimos no período de safra do açaí, fruto dos atos cooperativistas.

Apesar de $61 \%$ dos cooperados considerarem como boa a qualidade dos produtos da Cooperativa, apontam a existência de dificuldades para a comercialização. Dentre os fatores, identificam a concorrência de mercado, com empresas do mesmo segmento, mas com uma estrutura de capital mais sólida, além dos atravessadores que interceptam a produção dos cooperados, oferecendo um retorno imediato (venda à vista), porém por um valor menor que o oferecido pela Cooperativa.

Observou-se que a Cofruta não possui capital de giro suficiente para movimentar a capacidade de produção de seus cooperados, mostrando-se como um aspecto limitador, mas, ao mesmo tempo, possui um potencial de ampliação de mercado.

Os cooperados apontaram ainda como principais limitadores da Cofruta dificuldades decorrentes de uma política de divulgação de seus produtos (marketing), o que implica uma estrutura de comercialização associada à falta de entrepostos para a exposição de seus produtos nos centros consumidores.

A inadimplência da Cooperativa, a necessidade de prazos dilatados, exigidos pelos clientes para pagamento, os contratos de grandes quantidades e a dificuldade em manter a regularidade do fornecimento se constituem em fragilidades relativas à comercialização dos produtos da cooperativa e, em consequência, à sustentabilidade da mesma.

A Cofruta comercializa sua produção ao governo (federal) e ainda indica as instituições (escolas, creches etc.) para o consumo de seus produtos devido à comercialização no mercado institucional, através de convênios e acordos como o Programa de Aquisição de Alimentos 
(PPA) via Companhia Nacional de Abastecimento (Conab). Também possui relevante exportação para os estados do Rio de Janeiro e São Paulo, fatores esses que se explicam pelo nível de articulação em rede, ou seja, a dimensão política.

Para Singer (2002) e Coraggio (2003), o apoio não mercantil aos EES em sua constituição e/ou estruturação é de fundamental importância, tanto para seu surgimento, quanto para seu desenvolvimento. Estes autores comentam que o apoio é estratégico até o momento em que o empreendimento consegue gerar receitas capazes de cobrir todos os seus custos e manter uma regularidade de rendimentos que garantam sua viabilidade e sobrevivência futura.

No caso específico da Cofruta, no aspecto dos subsídios governamentais, destacamse os projetos aprovados em escala federal, como o PAA, que é uma ação do "Fome Zero", coordenado pelo Ministério do Desenvolvimento Social (MDS), via Companhia Nacional de Abastecimento (Conab), no apoio à comercialização, já citado. Na escala estadual, logo no início, teve apoio equivalente a $\mathrm{R} \$ 195$ mil, provenientes do Fundo de Desenvolvimento do Governo Estadual (FDE), através do Banco do Estado do Pará (Banpará), além de projetos de apoio à infraestrutura, na construção da agroindústria e na compra da câmara fria e suporte ao capital de giro, entre outros.

No aspecto dos subsídios não governamentais, destacam-se projetos de apoio à infraestrutura com empresas como a Natura, ${ }^{9}$ e de ONGs como a Federação de Órgãos para Assistência Social e Educacional (Fase), que contribuiu com R\$ 10 mil, assim como a Embaixada Britânica, que colaborou com a importância de $\mathrm{R} \$ 45$ mil, ambos para dar suporte às atividades iniciais da Cooperativa.

Não diferentes dos demais, os apoios não monetários (ou não financeiros) também foram importantes para a sustentabilidade da Cofruta, dos quais se destacam as doações ou cessões não monetárias, como máquinas e equipamentos, realizadas pela Adempa e pela Amazon Drin; a cessão do imóvel onde funciona a sede da cooperativa, assim como a organização dos agricultores, feita pelo STR de Abaetetuba; a orientação de plantio feita pela Secretaria de Agricultura do Estado (Sagri); a cessão do espaço para realização de cursos, oficinas e reuniões da cooperativa, realizada pelo Centro de Treinamento em Tecnologias Alternativas (Tipiti); cursos de qualificação profissional, técnica e gerencial; formação sociopolítica; assessoria jurídica e de gestão, desenvolvidas pela Fase e pela Universidade Federal do Pará (UFPA) via ITCPES, por meio de projetos de extensão universitária.

\subsection{A dimensão social}

Segundo Gaiger (2003), os aspectos internos dos empreendimentos se sobressaem, tendo em vista que representam os principais motores da articulação e mobilização dos laços iden-

\footnotetext{
${ }^{9}$ Tem, atualmente, como principal cliente a Natura, que só em 2009 comprou 256 toneladas de açaí in natura, além de diversas sementes como muru-muru, miriti (buriti), bacaba, patauá e andiroba.
} 
titários, possibilitando a convivência fraterna e solidária entre os cooperados. Neste sentido, percebe-se que a Cofruta tem sua origem primeira nas Comunidades Eclesiais de Base (CEBs), quando eram desenvolvidas ações e atividades sociais e coletivas que constituem a fonte das experiências de organização social e de cooperação comunitária.

Pode-se dizer que o âmbito social da Cofruta é um espaço rico em inter-relações, na medida em que se trata de um grupo social com cultura arraigada à região. Sua população resultou de processos de miscigenações mais antigas do estado, isto é, desde a colonização. Certamente esses elementos interferem decisivamente na constituição da organicidade existente do empreendimento e, assim, na sustentabilidade.

Por sua vez, Coraggio (2003) afirma que as relações sociais determinam a própria forma de organização do trabalho, particularmente quando se trata de um empreendimento rural, em que estão permeadas relações de parentesco, de vizinhança, reforçadas ainda pela relação direta com a natureza, exigindo um esforço de cooperação entre os agricultores familiares devido às adversidades e à ausência de instrumentos de trabalho.

Desta forma, a sustentabilidade da Cofruta, nessa dimensão, foi analisada com base em dois componentes básicos: o padrão de sociabilidade e o grau de coesão social. O primeiro diz respeito à maneira como as pessoas se relacionam no interior de uma organização e, no caso da Cofruta, se identificou que existe um equilíbrio entre a relação pessoal e a profissional, fato que, segundo os próprios cooperados, ajuda no desenvolvimento dos trabalhos da cooperativa.

No entanto, pode-se identificar que, mesmo que haja uma relação de mais de 30 anos de convivência, ainda persistem situações de concorrência entre os cooperados, provocada, muitas vezes, pela ambição e vaidade, mas também pela prática mercadológica, que acaba contribuindo para atitudes individualistas no interior da cooperativa, prejudicando assim a democracia interna e, por conseguinte, as práticas de cooperação.

A situação de concorrência é mais evidenciada com o aparecimento dos "atravessadores" que "seduzem" os cooperados ao oferecer pagamento à vista pelos seus produtos, afetando com isso a venda à própria Cooperativa, em sua dimensão econômica, que também pode ser correlacionada com o grau de coesão social. Percebe-se, portanto, certa deficiência da sustentabilidade da Cofruta sob o aspecto social.

\subsection{A dimensão política}

Para França Filho e Laville (2004), um dos elementos que distingue os empreendimentos econômicos solidários é a dimensão política. Essa dimensão está ligada ao aspecto interno, evidenciado por meio de indicadores como democracia interna, pela qual os cooperados, de forma democrática, podem participar do processo de gestão, e o grau de compromisso que verifica se os cooperados estão ou não comprometidos com os objetivos do grupo, representando a própria missão ou objetivos da cooperativa. 
Na Cofruta, nesse aspecto, 59\% dos cooperados sinalizaram que as decisões são tomadas em Assembleia Geral, na qual todos têm direito a um voto de maneira democrática; segundo $67 \%$ dos entrevistados, o processo de informação é transparente. No entanto, as dificuldades de locomoção e a distância entre as casas dos cooperados geram três níveis de organização: o primeiro entre os membros de cada setor, o segundo entre os coordenadores dos setores com a diretoria da Cooperativa e, finalmente, o terceiro em Assembleia Geral, com todos ou com a maioria dos cooperados, na qual são deliberadas as decisões de maneira democrática, de acordo com os interesses da coletividade.

Apesar dessa organização voltada à tomada de decisões de modo democrático, os dados da pesquisa de campo revelam que, dos cooperados da Cofruta, apenas $10 \%$ deles consideram "muito boa" a frequência nas assembleias, com opiniões e sugestões, $20 \%$ consideram "muito boa". Desta forma, ao fazer correlação com o nível de planejamento da dimensão gestão, observa-se que a baixa participação nas discussões abre precedente para que as decisões passem a ser consideradas antidemocráticas.

Quanto ao nível institucional, referente à existência de ação pública, os dados relatam que a Cofruta tem participação direta e indireta de movimentos sociais e populares, com destaque para movimentos ambientalistas, movimentos comunitários, movimentos de luta pela terra e pela agricultura familiar, movimentos de luta por moradia, movimentos pela igualdade racial, movimento religioso ou pastoral e, principalmente, movimento sindical rural. Este fato fortalece consideravelmente a sustentabilidade quanto ao aspecto da ação pública (França Filho e Laville, 2004).

É possível identificar essa cooperativa como líder entre as demais cooperativas da região, tendo em vista o papel de articulador das demais cooperativas nas demandas de políticas públicas de caráter territorial.

\subsection{A dimensão gestão}

A gestão é um processo estruturado, interativo e consolidado de planejamento e operacionalização das atividades de modo organizado, com direção e controle, visando o desenvolvimento sustentável do empreendimento; é coerente, nesse sentido, identificar a relação existente entre a gestão e a sustentabilidade em EES. Desta forma, para a compreensão da dimensão gestão, em termos da análise sobre a sustentabilidade da Cofruta, ela foi dividida nos componentes administrativos, cujos indicadores de análise são: o nível de planejamento, o nível de organização, o nível de direção, o nível de controle e autogestão, cujo indicador de análise é o nível de autonomia.

Quanto ao processo administrativo, em relação ao indicador nível de planejamento, $100 \%$ dos cooperados identificam que a Cofruta possui planejamento. Ressalta-se, ainda, que existe um planejamento prévio dos setores, no qual é definida a capacidade de produção de cada cooperado, e do setor como um todo, para, posteriormente, ser consolidado em um pla- 
nejamento maior (de um ano), do qual fazem parte todos os setores representados por seus coordenadores.

Nesse planejamento são discutidas as demandas da cooperativa e como cada setor poderá contribuir. Essa prática é essencial para o desenvolvimento da sustentabilidade da Cofruta, evitando que a cooperativa deixe de honrar seus contratos.

Em relação ao indicador nível de organização, 64\% dos cooperados apontam a existência de um processo organizacional responsável pela distribuição das tarefas e responsabilidades, porém $50 \%$ não sabem informar como esse processo se dá.

Para 30\% dos cooperados, essa organização é definida nos próprios setores de produção; outros 7\% apontam que são nas reuniões e Assembleias. Com isso, percebe-se que o processo organizacional da Cofruta se encontra pouco claro, na medida em que o planejamento se dá de modo parcelado, nos setores e, em seguida, na própria sede da cooperativa, dificultando a visibilidade e a transparência para o conjunto dos cooperados.

Para o indicador nível de direção, foi identificado que na Cofruta as instâncias de direção e coordenação estão dispostas em Assembleia Geral e reunião do coletivo dos Sócios, Diretoria, Conselho Diretor e Coordenação (produção, fábrica), Conselho Fiscal, Conselho Administrativo e Coordenação de Setores.

Quanto ao indicador nível de controle, de acordo com os dados coletados, os cooperados da Cofruta perceberam que, para desenvolver a sustentabilidade no aspecto da gestão, não basta apenas planejar as ações, pois é preciso executá-las de maneira organizada e dirigida e controlar a execução para verificar o planejado (Tenório, 2006). Segundo os cooperados, esse controle se dá pelas visitas e acompanhamentos do coordenador de produção nos setores, pela utilização de planilhas de acompanhamento financeiro e de produção e pela reunião de prestação de contas com os responsáveis pela produção.

De maneira geral, 73\% dos cooperados pesquisados avaliam o controle efetuado pela Cofruta como eficiente, fato apontado como ponto positivo para o processo de sustentabilidade da mesma. Todavia, os cooperados apontam dificuldades para atingir a eficiência do controle, e, mais uma vez, a distância entre os setores de produção provoca deficiência na comunicação.

No componente autogestão, o indicador nível de autonomia demonstrou que $90 \%$ dos cooperados acreditam que a Cofruta possui autonomia para decidir seu próprio destino, porém precisa de apoio de parceiros, por meio de assessorias. Nesse sentido, para 31\% dos entrevistados a Fase é a principal parceira. Em seguida, apontam o STR de Abaetetuba (21\%), a ITCPES/UFPA (18\%), a Emater (11\%) e a Sagri (11\%), mostrando a importância de articulação com as redes institucionais de formação e assistência técnica como elementos da sustentabilidade da Cofruta.

Para França Filho e Laville (2004), a autonomia institucional significa que as iniciativas não são sujeitas ao controle de outras instituições e possuem uma gestão própria e independente, porém não excluem a possibilidade de parcerias ou arranjos institucionais de cooperação, desde que a autonomia seja preservada.

Percebe-se que, embora haja problemas em relação às questões de informação e comunicação, a Cofruta consegue ter um nível de gestão planejada e articulada em diferentes as- 
pectos, pois consegue garantir o funcionamento da assembleia geral como espaço central das decisões mais importantes e das diretrizes para o planejamento, bem como a organização dos núcleos de cooperados garante o controle da produção, a identificação da origem dos produtos e de seus produtores, além de se constituir como uma das instâncias de gestão da Cofruta, mas especificamente na relação direta com a base da produção e da cooperação.

Essas atividades decorrentes do processo de organização da produção e da gestão possibilitam estabelecer a gestão como uma das dimensões da sustentabilidade da Cofruta, pois é neste espaço que são traçadas as estratégias relativas à inovação de produtos e estabelecimento de metas quanto à ampliação ou não de sua escala de mercado. Hoje a Cofruta, por sua capacidade de gestão e política, tem acesso ao mercado institucional e à venda de seus produtos para a merenda escolar, um dos pilares de sua própria sustentabilidade econômica, pois se trata de um mercado estável e com perspectivas duradouras.

\subsection{A dimensão formação}

A dimensão formação, subdividida nos componentes associativismo/cooperativismo e conhecimentos técnicos, teve como objetivo avaliar o processo de incubação da Cofruta, desenvolvido pela ITCPES/UFPA, a qual foi observada a partir de dois pontos de vistas. O primeiro se configurou com base na percepção dos cooperados da Cofruta, evidenciando conquistas e desafios desse processo em busca de sua sustentabilidade. O segundo partiu da equipe da Incubadora, numa tentativa de autoavaliação relativa ao uso da metodologia de incubação desenvolvida pela mesma, evidenciando pontos fortes e falhos desse processo.

Partindo desse raciocínio, quando questionados quanto ao entendimento do processo de incubação, 70\% dos cooperados entrevistados informaram não saber o que significa. Esta descrição foi uma das primeiras preocupações provocadas pela pesquisa, uma vez que a Incubadora desenvolve o acompanhamento da Cofruta há, praticamente, oito anos, sendo quatro voltados à incubação e os outros quatro a partir de assessorias esporádicas, tendo em vista que a mesma passa por processo de desincubação. Assim, analisando os dados relativos àqueles cooperados que conhecem o processo de incubação, 61\% avaliaram como boa a atuação da Incubadora.

Em relação às atividades desenvolvidas, 22\% identificam que a ITCPES tem uma melhor atuação no item capacitação profissional (com cursos e treinamentos); 17\% na assessoria/acompanhamento à gestão; $12 \%$ na assessoria/acompanhamento à produção; o restante ficou bastante fragmentado em: auxílio na elaboração de projetos (8\%), assessoria técnica na área de plantio (5\%) e assessoria comercial (4\%).

Em outro questionamento, mais focado nas áreas que a ITCPES contribuiu com a Cofruta, destacou-se o melhoramento do processo de produção (com a diversificação e aumento da produção, implantação de boas práticas, embalagens, dentre outros). Outra área de destaque foi relativa ao apoio à gestão, envolvendo os itens planejamento, organização, direção e controle, formação de redes e parcerias, marketing, comercialização dos produtos, conquista de 
novos clientes, formação de preço e conhecimento do custo dos produtos, prestação de contas, com a elaboração de planilhas e controles financeiros, elaboração do plano de negócios, estatuto e regimento interno.

Também foi lembrada a formação cooperativista e associativista desenvolvida pela equipe da Incubadora, pois quando perguntados sobre os princípios cooperativistas (45\%) dos cooperados entrevistados, demonstraram conhecimentos e 55\% desconhecem ou não têm informação de como são aplicados na Cofruta.

Os cooperados entrevistados sugeriram acompanhamento mais efetivo após os cursos e as oficinas, a fim de melhorar o processo de incubação desenvolvido pela ITCPES/UFPA. Eles comentaram que não basta apenas ministrar cursos e oficinas; há a necessidade de um acompanhamento por parte da equipe, para avaliar a implementação prática do que foi trabalhado no curso/oficina, o que significa desconhecimento do processo de incubação, o qual consiste na formação e na assistência técnica para acompanhamento do processo de aplicação do aprendizado.

Outra sugestão dos entrevistados para o melhoramento do processo de incubação foi que os cursos e oficinas precisam ser realizados com os demais cooperados que estão longe da sede e do processo produtivo (agroindústria). ${ }^{10}$ Pois, devido à distância, a participação nos cursos tende a ser mais difícil, o que se explica mediante uma correlação com o item anterior, quando demonstra que $70 \%$ dos cooperados entrevistados não conhecem o processo de incubação desenvolvido pela ITCPES/UFPA, ou seja, se as atividades de incubação (cursos, oficinas e treinamentos), de um modo geral, não chegam até eles, então não conhecem o processo.

Num segundo momento da análise, tomou-se como base o ponto de vista da equipe da ITCPES, antes já comentado. Da amostra selecionada (30 membros) para esta pesquisa, 40\% fizeram ou fazem parte, direta ou indiretamente, do processo de incubação da Cofruta.

Quanto à sustentabilidade da Cofruta, 70\% da equipe pesquisada da ITCPES/UFPA acredita na sustentabilidade da mesma, porém 40\% considera a sustentabilidade "boa". Quando perguntados sobre a contribuição da Incubadora para a sustentabilidade da Cofruta, houve equilíbrio entre "boa", com 37\%, e "muito boa", com 33\%. Fato que explica o reconhecimento da equipe quanto aos desafios e às falhas no processo de incubação da Cofruta.

No entanto, ao se analisarem algumas das conquistas ou dos avanços da Cofruta, a equipe reconhece a contribuição no mix de produtos, o que torna a cooperativa com mais capacidade operacional para a inserção no mercado competitivo, fato este que, correlacionado à análise dos cooperados, sobre a contribuição da Incubadora à Cofruta, indica que o principal item foi o melhoramento do processo de produção (com a diversificação e o aumento da produção, e implantação de boas práticas). Outras contribuições da ITCPES/UFPA à sustentabili-

\footnotetext{
${ }^{10}$ Vale informar que a Incubadora já desenvolveu processos de formação nos setores de produção, os quais ficam em grande parte nas ilhas do município de Abaetetuba. No entanto, em função da logística de transporte, a formação é, geralmente, realizada no Centro de Formação Tipiti.
} 
dade da Cofruta, sinalizadas pela equipe, foram quanto à expectativa de renda e ao incentivo à gestão democrática e à articulação em redes locais, nacionais e internacionais.

Analisados os pontos positivos do processo de incubação da Cofruta, sob o ponto de vista da equipe, não se pode negar a importância de sua atuação para o processo de sustentabilidade; no entanto, como comentado, essa atuação tem falhas, ou poderia ter um melhor desempenho, de acordo com a análise dos dados coletados.

Esse panorama foi sinalizado pelo baixo percentual de conhecimento/informação sobre os conceitos e os procedimentos da metodologia de incubação e sustentabilidade. Pois, de acordo com a pesquisa, apenas $57 \%$ dos entrevistados da equipe da incubadora possuem conhecimento aprofundado sobre metodologia de incubação e apenas $37 \%$ conhecem com propriedade o conceito de sustentabilidade.

Por fim, acredita-se que no processo de incubação há a necessidade de a ITCPS dar maior atenção aos resultados das capacitações, realizadas por sua equipe junto aos empreendimentos, com avaliação periódica dos cooperados, envolvendo as ferramentas administrativas (planejamento, organização, direção e controle), tendo em vista que seu ponto de partida é a racionalidade substantiva apregoada por Guerreiro Ramos (1989), cuja centralidade são as pessoas da organização.

É necessário mostrar que a Incubadora trabalha com projetos e por essa razão a equipe é constantemente renovada, exigindo formação constante e contínua, com formação interna, com oficinas, seminários e reuniões da equipe; no entanto, a rotatividade é uma condição da própria estrutura da Incubadora como laboratório de ensino, pesquisa e extensão. Buscando amenizar esse problema, a Incubadora criou, desde 2004, a jornada de ensino, pesquisa e extensão, em que são discutidas as ações e atividades, além dos planos de trabalho, produção de conhecimento, dentre outros debates que se fizerem necessários, mas a rotatividade de técnicos e bolsistas é certamente um dos problemas da incubação.

\section{Considerações finais}

A sustentabilidade da Cofruta é estratégica para o desenvolvimento da microrregião do Baixo Tocantins, na medida em que exerce uma função de liderança no processo de organização dos trabalhadores rurais com base no trabalho associado. Trata-se, na realidade, de uma cooperativa líder em termos da articulação de uma rede de organização para a comercialização dos produtos regionais, que aglutina associações de produção e cooperativas de cinco municípios da microrregião do Baixo Tocantins.

O trabalho de incubação e, atualmente, de assessoria técnica à Cofruta visa contribuir para sua sustentabilidade, com a realização de ações pontuais, como cursos e oficinas para a elaboração de projetos de investimentos. Assim, a crítica dos cooperados, no sentido de que os treinamentos não são ofertados para o conjunto dos cooperados, dá-se, em princípio, em função da nova relação da Incubadora com esta cooperativa, ou seja, o processo de desincu- 
bação, que consiste no momento em que o empreendimento tem condições de se autogerir, embora existam lacunas.

Outro elemento importante de se evidenciar é o fato de que a Incubadora não possui recursos próprios para desenvolver suas atividades. Suas ações dependem do acesso a editais, que muitas vezes não conseguem atender as demandas dos empreendimentos na proporção que eles necessitam; portanto, embora se avalie a importância de ações continuadas, o volume de recursos para os deslocamentos e a permanência nos espaços dos próprios empreendimentos não é suficiente para a vivência dos alunos, técnicos e professores nos núcleos de produção, como desejam os cooperados. Esse é realmente um limite para o processo de incubação.

Essa realidade é objeto de análise dos relatórios e documentos encaminhados pela Incubadora aos órgãos de fomento. Busca-se com esses relatos sensibilizar esses órgãos para as questões locais e regionais, quando os baixos índices de serviços coletivos e de infraestruturas locais bloqueiam até mesmo as iniciativas dos sujeitos, como as cooperativas, em que pese os limites de suas ações que têm contribuído efetivamente para a melhoria das condições de vida em seus territórios.

Para finalizar, entende-se que a Cofruta vive um momento importante na consolidação de sua sustentabilidade, pois já tem uma década de existência e observa-se a projeção desse empreendimento em termos de sua inserção em novas escalas de mercado, mostrando desta forma sua sustentabilidade na medida em que se analisaram as diferentes dimensões, estruturadas como indicadores de sua manutenção na vida econômica, política, cultural e social do empreendimento na região, caracterizando como um instrumento de desenvolvimento na perspectiva da sustentabilidade.

\section{Referências}

BARBOSA, Maria J. de S. Desenvolvimento rural e economia solidária: estratégia de sustentabilidade sob processos de intercooperação Espanha e Brasil na microrregião do Baixo Tocantins — na Amazônia brasileira. In: LÓPEZ, Daniel; BARBOSA, Maria José de S. (Org.). Estrategias y acciones de desarrollo rural a través de cooperativas y emprendimientos solidarios. Alicante: Aecid/UA/UFPA, 2012b. p. 169-192.

BARBOSA, Maria J. de S. Tecnologia social aplicada ao desenvolvimento da Amazônia. In: EID, Farid; BARBOSA, Maria J. de S.; ERDMANN, Rodrigo (Org.). Em debate: formação em engenharia, tecnologia social aplicada ao desenvolvimento da Amazônia. Belém: ICSA, 2012a.

BARBOSA, Maria J. de S. et al. A incubadora tecnológica de cooperativas populares e empreendimentos solidários da UFPA: uma articulação entre ensino, pesquisa e extensão. In: ZUART, Laudemir (Org.). Educação e socioeconomia solidária: interação universidade-movimentos sociais. Cáceres: Editora Unemat, 2006. p. 158-168. (Série Sociedade Solidária, v. 2). 
BARDIN, Laurence. Análise de conteúdo. Lisboa: Setenta, 1977.

BRANDÃO, Carlos R. (Org.). Pesquisa participante. São Paulo: Brasiliense, 1981.

BRASIL. Lei no 5.764, de 16 de dezembro de 1971. Disponível em: <www.planalto.gov.br> . Acesso em: 13 abr. 2009.

COOPERATIVA DOS FRUTICULTORES DE ABAETETUBA (COFRUTA). Estatuto social. Abaetetuba, 2002. Mimeografado.

CORAGGIO, José L. Economia do trabalho. In: CATTANI, Antonio D. (Org.). A outra economia. Porto Alegre: Veraz, 2003. p. 122-128.

CRESWELL, John W. Projeto de pesquisa: métodos qualitativo, quantitativo e misto. 2. ed. Porto Alegre: Artmed, 2007.

EID, Farid. Análise sobre processos de formação de incubadoras universitárias da Unitrabalho e metodologias de incubação de empreendimentos de economia solidária. In: DAL RI, Neusa M. (Org.). Trabalho e educação: arquitetos, abelhas e outros tecelões da economia popular solidária. São Paulo: Ideias \& Letras, 2004. v. 1, p. 167-188.

EID, Farid. Economia solidária, desenvolvimento organizacional e cooperativismo rural. In: LÓPEZ, Daniel; BARBOSA, Maria José de S. (Org.). Estrategias y acciones de desarrollo rural a través de cooperativas y emprendimientos solidarios. Alicante: Aecid/UA/UFPA, 2012. p. 29-54.

EID, Farid; GALLO, Ana R. Metodologia de Incubação e desafios para o cooperativismo popular: uma análise sobre o trabalho da Incubadora de Cooperativas Populares da Ufscar. Ufscar, 2001. Mimeografado.

FRANÇA FILHO, Genauto de C.; LAVILLE, Jean-Louis. Economia solidária: uma abordagem internacional. Porto Alegre: Editora da UFRS, 2004.

FREIRE, Paulo. Que fazer: teoria e prática em educação popular. Petrópolis: Vozes, 1989.

GAIGER, Luiz I. A economia solidária diante do modo de produção capitalista. Caderno CRH, Salvador, v. 16, n. 39, p. 181-211. jul./dez. 2003.

GAIGER, Luiz I. Empreendimento econômico solidário. In: HESPANHA, Pedro et al. (Org.). Dicionário internacional da outra economia. CES, 2009. p. 181-187.

GIL, Antonio C. Métodos e técnicas de pesquisa social. 6. ed. São Paulo: Atlas, 2010.

GUERREIRO RAMOS, Alberto. A nova ciência das organizações. 2. ed. Rio de Janeiro: Editora da Fundação Getulio Vargas, 1989.

ITCPES. Relatório de acompanhamento às cooperativas populares e empreendimentos solidários. Belém: ITCPES/CSE/UFPA, 2008.

LAVILLE, Jean-Louis; GAIGER, Luiz I. Economia solidária. In: HESPANHA, Pedro et al. (Org.). Dicionário internacional da outra economia. São Paulo: Almedina; CES, 2009. p. 162-168. 
NUNES, Débora. Incubação de empreendimentos de economia solidária: uma aplicação da pedagogia da participação. São Paulo: Annablume, 2009.

REIS, Tatiana A. A sustentabilidade em empreendimentos da economia solidária: pluralidade e interconexão de dimensões. Dissertação (mestrado) — Universidade Federal da Bahia, Salvador, 2005.

SANTOS, Ariosvaldo dos; GOUVEIA, Fernando H. C.; VIEIRA, Patrícia dos S. Contabilidade das sociedades cooperativas: aspectos gerais e prestação de contas. São Paulo: Atlas, 2008.

SINGER, Paul. Introdução à economia solidária. São Paulo: Fundação Perseu Abramo, 2002.

SINGER, Paul; SOUZA, André R. de. A economia solidária no Brasil: a autogestão como resposta ao desemprego. São Paulo: Contexto, 2000.

TENÓRIO, Fernando G. (Org.). Gestão de ONGs: principais funções gerenciais. 10. ed. Rio de Janeiro: Editora FGV, 2006.

THIOLLENT, Michel. Metodologia da pesquisa-ação. 14. ed. São Paulo: Cortez, 2005.

WELLEN, Henrique. Para a crítica da economia solidária. São Paulo: Outras Expressões, 2012.

Anderson Roberto Pires e Silva é mestre em administração e professor assistente II da Faculdade de Ciências Contábeis da Universidade Federal do Pará (UFPA). E-mail: andersonpires@hotmail.com.

Maria José de Souza Barbosa é doutora em serviço social e professora adjunta da Faculdade de Serviço Social da Universidade Federal do Pará (UFPA). E-mail: majose@ufpa.br.

Francivaldo dos Santos Albuquerque é especialista em docência do ensino superior e professor auxiliar I da Faculdade de Ciências Contábeis da Universidade Federal do Pará (UFPA). E-mail: valdo_wh@ hotmail.com. 
